\title{
A Teoria Crítica e os Novos Desafios Contemporâneos: globalização, cosmopolitismo e democracia
}

Fernando Perlatto'

\section{Resumo}

As últimas décadas têm testemunhado um crescimento significativo de reflexões sobre a globalização e o cosmopolitismo no campo da teoria social. Dentre os esforços realizados nesse sentido, destacam-se os trabalhos de autores vinculados à teoria crítica, a exemplo de Jürgen Habermas, Nancy Fraser, Seyla Benhabib e Craig Calhoun. No presente artigo, objetivamos analisar suas reflexões sobre essas temáticas, demonstrando como suas obras mais recentes, a despeito das diferenças e particularidades, se aproximam no sentido de buscarem compreender de maneira dialética, à luz da teoria crítica, os processos de globalização e de configuração do cosmopolitismo intensificados nos últimos anos. Pretendemos demonstrar que suas reflexões sobre essas temáticas contribuem para a construção de uma perspectiva crítica ao cosmopolitismo e à globalização contemporânea, sem que isso resulte no abandono de um projeto universalista, democrático e emancipatório.

Palauras-chave: Teoria crítica. Globalização. Cosmopolitismo. Democracia.

Independentemente do período que se estabeleça como marco inicial da teoria crítica - seja remetendo-se à produçáo de Marx no século XIX, seja associando-a à criação, nos anos 1920, do Instituto de Pesquisa Social, em Frankfurt, e os trabalhos subsequentes produzidos por Horkheimer e Adorno -, é notável perceber seus desdobramentos e desenvolvimentos posteriores, logrando se estabelecer, ao longo do século XX, como uma das principais vertentes de reflexão no campo da teoria social. Ainda que o rótulo "teoria crítica" seja amplo, servindo para designar diferentes produções, "modelos" e

Doutor em Sociologia pelo Instituto de Estudos Sociais e Políticos (IESP-UERJ) e Professor do Departamento e do Programa de Pós-Graduação em História da Universidade Federal de Juiz de Fora (UFJF).

E-mail:fperlatto@yahoo.com.br 
vertentes teóricas (CALHOUN, 1995; MÜLLER-DOOHM, 2005), é possível agrupar em seu entorno autores que procuraram compreender de forma crítica a modernidade e suas instituiçôes, buscando elaborar uma crítica imanente e refletir sobre os impasses e as aporias da vida moderna, assim como inquirir sobre os sujeitos e as forças potenciais de produção da crítica política e da emancipação social. Não obstante suas particularidades, os autores vinculados à teoria crítica se aproximam pela formulação de um enfrentamento contundente ao capitalismo e às suas diferentes formas de opressão, sem descurar, contudo, de refletir sobre barreiras reais e concretas existentes para a construção de uma nova ordem social (BENHABIB, 1986).

Diferentes autores vêm destacando as mudanças processadas, ao longo das últimas décadas, no campo da teoria crítica. Como tem sido demonstrado, estas mudanças estiveram vinculadas, em grande medida, às próprias transformaçóes que ocorreram no mundo em tempos recentes, sobretudo a partir do final dos anos 1970 e da década 1980, a exemplo do fim do chamado "socialismo real", da crise do marxismo e do avanço do neoliberalismo, mudanças estas que, de diferentes maneiras, colocaram novos desafios para os autores vinculados à teoria crítica. Frente a essas transformaçóes, como bem destacado por Marcos Nobre (2012), novas formulaçóes foram desenvolvidas de sorte a atualizar ou, de outra parte, problematizar, a análise de categorias que serviram como uma espécie de substrato para a teoria crítica ao longo do século XX, como as de "ideologia", "alienação", "reificação" ou "exploração". Dessa forma, ainda que recorrendo à tradiçáo dos autores clássicos, a produção teórica e empírica relacionada à teoria crítica vem buscando renovar olhares e abordagens no sentido de compreender, a partir de novas perspectivas, as mudanças que ocorreram no mundo ao longo das últimas décadas (DOMINGUES, 2011).

Dentre essas mudanças intensificadas no final do século $\mathrm{XX}$, merece destaque particular o recrudescimento dos processos de transformação relacionados ao avanço da globalização, que vêm colocando novos desafios aos Estados e às identidades nacionais como decorrência do surgimento e/ou do agravamento de situaçóes-problema que extrapolam as fronteiras nacionais (BAUMAN, 1998; ROBERTSON, 2002). A sociedade mundial que emerge neste novo cenário resulta, ao mesmo tempo em que impulsiona, a configuração de "novos lugares" que não mais se confundem com o Estado nacional 
e suas fronteiras nacionais rígidas e bem delimitadas (REIS, 2009). Trata-se, em grande medida, da configuração de uma variedade imensa de lugares conectados entre si, cujos sujeitos estabelecem novos circuitos de comunicaçáo e trocas, assim como renovadas formas de circulaçáo de pessoas e produtos. A globalização, nesse sentido, significa, como bem destacado por Ülrich Beck na ativação de processos nos quais os Estados nacionais "vêem a sua soberania, sua identidade, suas redes de comunicação, suas chances de poder e suas orientaçôes sofrerem a interferência cruzada de atores transnacionais" (BECK, 1999, p. 18).

Essas agendas de mudanças impulsionadas pela globalização e pela emergência de atores transnacionais vêm impactando de forma significativa a reflexão no âmbito da teoria social. Conforme ressaltado por Renato Ortiz (2008), conceitos como "identidade nacional”, "partidos", "história nacional”, "modernização", formulados em um contexto no qual a ideia da nação conferia unidade integradora aos processos sociais, têm ficado comprometidos para a análise das sociedades contemporâneas. $\mathrm{O}$ alargamento da sociedade global e o surgimento de um novo "lugar" - o mundo - definiriam uma situação na qual se tornaria imperativa a superaçáo dos contextos "regionalizados" para a análise dos processos sociais, promovendo-se, consequentemente, um rearranjo das formas pelas quais a teoria social se desenvolveu até os dias atuais. Isso explicaria, em grande medida, o movimento, que vem ganhando cada vez mais força nos últimos tempos, no sentido de promover uma revisão conceitual no âmbito da teoria social e repensar categorias e conceitos que, historicamente, foram formulados ancorados no âmbito do "nacionalismo metodológico" (BECK, 2006). Este movimento vem ensejando uma busca mais ampla no sentido da construçáo de uma "sociologia global", que seja capaz de responder aos desafios colocados na agenda contemporânea, que transcendem as fronteiras nacionais (BURAWOY et al., 2010).

É importante destacar a emergência de vozes antagônicas no debate mais geral sobre a possibilidade da construçáo de um marco explicativo capaz de dar conta de interpretar as transformaçóes globais. De um lado, autores que compreendem a globalizaçáo apenas em uma chave positiva, como se a adesáo acrítica dos países aos processos de integração transnacionais, sobretudo pela via do mercado, fosse a panaceia para a resoluçáo dos problemas enfrentados pelos Estados nacionais. Constrói-se, nesse sentido, um cenário idílico da 
globalização, rejeitando-se por completo as instituiçóes, os valores e as tradiçóes associadas aos Estados nacionais, apostando-se todas as fichas no cosmopolitismo, perdendo-se, consequentemente, de vista as relaçóes de poder, as assimetrias e as desigualdades constituídas e fortalecidas nos processos de integração global em curso. De outro lado, em uma visão oposta, estão aqueles autores que procuram interpretar, a partir de diferentes perspectivas, os processos associados à globalizaçáo somente em uma perspectiva negativa, como se neles estivessem contidos apenas e necessariamente elementos associados à opressão e à repressão. Em grande medida, estas interpretaçóes, a despeito de suas diferenças, encaram o processo de globalização - e conceitos a ele correlatos, a exemplo de transnacionalizaçáo e cosmopolitismo - como um movimento associado exclusivamente ao avanço do capital financeiro internacional e das grandes empresas, cujo resultado único e necessário seria o enfraquecimento, quando náo, o fim das soberanias nacionais. A ideia de universalidade, nesse sentido, estaria sempre associada à coerção contra os particularismos nacionais e locais. Em uma chave invertida de leitura, é possível dizer que essas interpretaçóes acabam por associar a nação à ideia de virtude e a globalização ao seu oposto, reduzindo-se, por um lado, os elementos de repressão associados à nação e perdendo-se de vista, por outro, os aspectos potencialmente emancipatórios e democráticos contidos na agenda universalista e cosmopolita.

Este artigo abordará os autores associados ao campo da teoria crítica, que vêm procurando destacar os aspectos contraditórios e as ambivalências da globalizaçáo. Procuraremos, ao longo deste texto, discutir as reflexóes de alguns autores relevantes da teoria crítica contemporânea que têm buscado construir uma crítica imanente à globalização, apontando para as suas contradiçóes, limites e potencialidades, contribuindo, dessa forma, para problematizar, de uma parte, a aceitação acrítica da agenda universalista, aventada pela globalização, como se houvesse uma necessária facticidade na sua promessa de integração democrática; e, de outra, a defesa intransigente do nacionalismo e dos particularismos, como se o discurso cosmopolita devesse ser visto somente como uma retórica a justificar a opressão dos países "centrais" sobre os "periféricos".

Para realizar esta discussão, em primeiro ligar, (I) buscaremos abordar, em uma perspectiva mais ampla, diagnósticos sobre a globalização no âmbito da 
teoria crítica, dando destaque especial para a análise de Nancy Fraser em torno do paradigma "pós-westfaliano" de justiça. O intuito será o de demostrar de que maneira sua interpretação crítica acerca dos processos de integraçáo transnacionais em curso não descura de perceber as possibilidades de emancipação que se abrem com as novas relaçóes que se estabelecem com o recrudescimento da globalização. Posteriormente, (II) dedicaremos a análise às abordagens sobre cosmopolitismo que ganharam relevância na teoria crítica nos últimos anos, com foco especial nas reflexôes de Jürgen Habermas sobre o tema e sua aposta nas potencialidades democráticas e emancipatórias inscritas na "sociedade mundial de cidadãos” para a superação do déficit de integração social em âmbito transnacional. Em seguida, (III) centraremos a atenção sobre os trabalhos de Seyla Benhabib e (IV) Craig Calhoun, que, nas trilhas abertas por Habermas, construíram reflexóes sobre o tema cosmopolitismo críticas aos processos de globalização, sem, contudo, deixar de valorizar os elementos potencialmente democráticos e emancipatórios contidos na agenda cosmopolita. À guisa de conclusão, $(V)$ buscaremos discutir de que maneira que as interpretações de Fraser, Habermas, Benhabib e Calhoun sobre a globalização, ainda que a partir de diferentes perspectivas, ao rejeitarem os extremismos nacionalistas e internacionalistas, contribuem para problematizar os limites e as aporias dos processos de integração e transnacionalização impulsionados nas últimas décadas, ao mesmo tempo em que apontam para as potencialidades existentes na agenda cosmopolita para a ampliaçáo das reivindicaçóes e conquistas democráticas.

\section{I}

Ao longo das últimas décadas, a teoria social tem buscado compreender as mudanças vinculadas ao que se convencionou interpretar como uma nova fase da modernidade, marcada pela transformaçáo dos modos de acumulaçáo e regulação do capitalismo, pela crise do modelo fordista e pelo avanço dos processos de globalização (DOMINGUES, 2011, p. 76). Seja interpretando-a a partir de termos como "alta modernidade" ou "modernidade tardia" (GIDDENS, 1990), "modernidade reflexiva" (BECK et al., 1995), "terceiro espírito" do capitalismo ou "terceira fase" da modernidade (BOLTANSKY; CHIAPELLO, 1994; DOMINGUES, 2002), diferentes autores vêm procurando compreender as principais características da modernidade flexível, que 
se impôs a partir dos anos 1970, e que teve na globalização e nos processos de integração transnacionais seus impulsos principais. A partir de uma perspectiva crítica diversos trabalhos têm buscado diagnosticar as características deste "novo mundo" configurado a partir dos anos 1970, a exemplo das interpretações de Zygmunt Bauman sobre o mundo líquido e as ambivalências da modernidade, de Clauss Offe e de Habermas sobre a perda da centralidade do mundo do trabalho, de Manuel Castells sobre a sociedade em "rede", de Imannuel Wallerstein sobre o sistema-mundo, de Nestor Canclini sobre culturas híbridas e conflitos multiculturais da globalização, de Stuart Hall sobre a identidade na pós-modernidade, de Boaventura de Souza Santos sobre a democracia contemporânea, de Negri e Michael Hardt sobre as transformaçóes do império, da multidão e da noção de comum, e de Frederic Jameson, David Harvey e Jean-François Lyotard sobre a cultura na pós-modernidade.

A partir da análise da atual fase da modernidade, a teoria crítica também tem objetivado construir uma perspectiva normativa de uma solidariedade cosmopolita de alcance mundial, que tenha como elemento central o estabelecimento de uma ordem mundial justa (VANDENBERGHE, 2011, p. 86). Uma das interpretaçóes mais sofisticadas sobre esta nova fase da modernidade flexível, produzida no campo da teoria crítica, é a teoria “pós-westfaliana” de justiça, proposta por Nancy Fraser, nos artigos que compóem obras como Reframing Justice e Scales of Justice. Reimagining Political Space in a Globalizing World. De acordo com a perspectiva crítica proposta por Fraser, a globalização e os processos de transnacionalização intensificados a partir dos anos 1970 teriam alterado profundamente a forma de se compreender a questáo da justiça no mundo contemporâneo. Neste novo cenário emergente, tanto as decisóes tomadas em um Estado nacional impactariam pessoas que se encontram fora de suas fronteiras, quanto as açóes de corporaçóes e organizaçóes supranacionais, de especuladores financeiros internacionais e dos grandes investidores transnacionais acabariam por afetar diretamente as vidas daqueles que estão dentro de territórios nacionais. De acordo com Fraser, os desafios colocados na agenda contemporânea - relacionados a temáticas diversas como o aquecimento global, a disseminação de doenças, a expansão do terrorismo internacional e a ampliação do poder das agências de mercado internacionais segundo a autora - resultaria, em um novo tipo de vulnerabilidade social, demandando, consequentemente, soluçóes que transbordariam as fronteiras nacionais. 
Frente a este novo cenário, de acordo com Fraser, a reflexão sobre a questão da justiça não poderia mais se prender às fronteiras internas dos Estados nacionais, devendo antes ser compreendidas em termos de "pluralidade de escalas de justiça”, abarcando injustiças regionais, nacionais e globais, que se inter-relacionariam. Se no período do auge do Estado de Bem-Estar Social que cobre o período do pós-guerra e se prolonga até os anos 1970 -, os conflitos acerca da justiça haviam se concentrado naquilo que Fraser denominara de "enquadramento Keynesiano-Westfaliano" - com isso querendo aludir a uma determinada forma de se conceber a justiça como referida ao interior das fronteiras nacionais e aos cidadáos vinculados a determinados territórios específicos -, as últimas décadas teriam testemunhado mudanças significativas, que implicaram na necessidade de uma nova compreensão das demandas por justiça pensada em termos de "interseção de diferentes escalas", adquirindo, por conseguinte, dimensões transnacionais (FRASER, 2008).

Segundo Fraser, no contexto de vigência do "enquadramento Keynesiano-Westfaliano", as lutas por justiça se davam em torno de duas grandes agendas, quais sejam: as reivindicaçôes por redistribuição socioeconômica e as exigências por reconhecimento legal ou cultural. Nesta perspectiva, as disputas ocorriam especialmente em torno do que era a justiça, sendo pouco ou nada relevante o debate sobre a quem a justiça deveria ser direcionada ou por quem ela deveria ser construída, na medida em que já se dava como aceito que ela se vincularia aos cidadãos de determinados territórios nacionais. Contudo, com a crise do "enquadramento Keynesiano-Westfaliano", a gramática das reivindicaçóes por redistribuição e por reconhecimento teve que ser alterada, passando a incluir a reflexão sobre o quem, na medida em que elas não mais se restringem às fronteiras nacionais. Para Fraser, neste novo contexto, as discussóes sobre a justiça passariam a se caracterizar por um duplo aspecto: por um lado, elas tratariam de "questóes de primeira ordem relativas à substância", vinculadas às disputas em torno da redistribuiçáo e do reconhecimento, como ocorria no paradigma "Keynesiano-Westfaliano"; por outro lado, elas também passaram a considerar "questóes de segunda ordem relativas ao metanível", vinculadas precisamente às disputas sobre o enquadramento no debate sobre justiça (FRASER, 2005).

O debate sobre enquadramento traria para a reflexão sobre a justiça a dimensáo da política, associada à "representação", que, ao lado do reconhecimento 
e da redistribuição, se converteria como variável fundamental para pensar a agenda da igualdade no enquadramento "pós-Westfaliano". Nesse sentido, que Fraser amplia sua teoria da justiça dimensional anteriormente formulada para pensar em uma teoria tridimensional, que além de pautar as lutas contra a "má distribuição" e o "falso reconhecimento", também embasaria a luta contra a "falsa representação". A representação se vincularia às regras procedimentais de debate, deliberação e decisão mediante as quais deveriam se estruturar, no mundo globalizado, as disputas sociais e simbólicas, envolvendo atores transnacionais. Dessa maneira, pensar a justiça no mundo globalizado contemporâneo demandaria, segundo Fraser, a configuração de arranjos sociais e institucionais paritários capazes de possibilitar a representaçáo e a participação plena de todos os grupos e indivíduos nas decisóes políticas, que transcenderiam as fronteiras nacionais. $\mathrm{O}$ novo enquadramento abriria caminhos para que os segmentos marginalizados pudessem problematizar e questionar as decisóes tomadas por poderes que estariam fora dos limites nacionais, vinculados às corporaçóes privadas transnacionais, aos especuladores internacionais e às estruturas de governança da economia global, que, na atualidade, não se encontrariam sobre um controle verdadeiramente democrático, a despeito das influências por elas desfrutadas nos processos decisórios nacionais (FRAZER, 2005).

Nessa perspectiva, de acordo com Fraser, as lutas por redistribuição e reconhecimento - questóes que ela denomina como de "primeira ordem" - somente poderiam ser enfrentadas caso as reivindicaçóes fossem articuladas aos embates relacionados ao enquadramento da representaçáo em âmbito global, que a autora denomina de questóes de "segunda ordem". Nesse novo enquadramento, um coletivo de pessoas se converteria em sujeitos da justiça não por suas proximidades geográficas per se, mas pelo pertencimento a um enquadramento comum transnacional, que estabeleceria as regras que governariam seus processos de interação social. Os movimentos sociais, impulsionados por uma política transformativa do enquadramento lutariam tanto contra a "má distribuiçáa" e a "ausência de reconhecimento", quanto contra a "falsa representação" de metanível, decorrente do mau enquadramento, reivindicando a reconstituição da dimensão quem da justiça. Tratar-se-ia, nesse sentido, de uma reivindicação pela institucionalização da paridade de participação no nível metapolítico. Nesse cenário, os movimentos sociais recusariam o estabelecimento do enquadramento como uma prerrogativa 
quer dos Estados nacionais, quer das elites transnacionais, procurando democratizar os processos mediante os quais os enquadramentos da justiça são desenhados e reivindicando a criação de novas arenas democráticas transnacionais, como, por exemplo, o Fórum Social Mundial. Seria precisamente a combinação das lutas por justiça em todas as escalas que permitira pensar em uma teoria pós-Westfaliana da justiça democrática (FRASER, 2008).

É justamente no sentido de refletir sobre as possibilidades de configuração de uma justiça "pós-Westfaliana” que Fraser, em diálogo crítico com Habermas, tem desenvolvido formulaçóes em torno do que denomina de "esfera pública transnacional". Se em contexto anterior, a autora já havia criticado a formulação original de Habermas em torno da categoria de "esfera pública", destacando que sua proposição original contida no livro Mudança Estrutural da Esfera Pública, centrada na esfera pública burguesa, desconsideraria outras esferas públicas existentes - que ela denominava de "counterpublic spheres" -, constituídas por segmentos excluídos da sociedade, como, por exemplo, as mulheres (FRASER, 1992), nos últimos anos Fraser tem problematizado as formulaçóes teóricas em torno da ideia de esfera pública, que, segundo ela, permaneceriam presas ao imaginário político "Keynesiano-Westfaliano", centrado nas fronteiras nacionais (FRASER, 2008). De acordo com a autora, faz-se necessária a reflexão em torno de um modelo deliberativo de esfera pública para o enquadramento pós-Westfaliano, no qual os processos de formação pública da opinião não se deem mais exclusivamente em termos nacionais, assegurando a reflexão tanto sobre quem vai efetivamente participar das deliberaçóes, que, no mundo globalizado, assumem características transnacionais, quanto sobre como assegurar a participaçáo paritária nesses processos deliberativos. Nesse sentido que Fraser aponta para o desafio duplo colocado para a teoria crítica contemporânea: por um lado, trata-se de pensar em como contribuir para identificar e impulsionar novos movimentos sociais transnacionais; por outro, trata-se de garantir que esses movimentos estejam conectados com novas esferas públicas transnacionais, assegurando que suas decisões se convertam efetivamente em decisóes políticas democráticas e emancipatórias (FRASER et al., 2014).

Dessa forma, é possível perceber as ambivalências e as contradiçóes que emergem da análise da teoria crítica formulada por Fraser para compreender os processos de globalização e de transnacionalização intensificados nas 
últimas décadas. Se por um lado, há a denúncia da intensificação dos mecanismos de exploração e de dominação, reconfigurados a partir do avanço do neoliberalismo, por outro, se verifica a construção de uma teoria tridimensional da justiça, que insere no centro da agenda reflexiva a temática da representação, dimensão política da justiça, ao lado do reconhecimento e da redistribuiçáo. Dessa forma, ao inserir o problema do enquadramento como variável fundamental para pensar as estruturas de governança e os procedimentos de tomadas de decisão em dimensão global, Fraser, ao mesmo tempo em que problematiza as configuraçóes de poder no mundo atual, abre caminhos importantes para a reflexão em torno de uma teoria crítica preocupada com a formulaçáa de uma agenda de resistência e de emancipaçáa que se preocupa náo somente com as questóes econômicas e culturais, mas também políticas, e que encontra na esfera pública transnacional seu espaço de deliberação e construção democrática.

\section{II}

Dentre os debates que tiveram desdobramentos mais relevantes no campo da teoria social relacionados à reflexão sobre a globalização e os processos de integração transnacionais, destaca-se aquele vinculado ao cosmopolitismo (COSTA, 2001). Nos últimos anos, diversos trabalhos têm procurando compreender, a partir de diferentes perspectivas e recortes teóricos, os processos de mudanças transnacionais, sob a chave reflexiva da "imaginação cosmopolita" (SANTOS, 2003; BECK, 2006; FINE, 2007; DELANTY, 2009, 2012; HARVEY, 2009; CHERNILLO, 2010; VANDENBERGHE, 2011). No âmbito da teoria crítica, dentre os esforços dedicados à interpretação do cosmopolitismo, merece destaque especial a reflexão de Jürgen Habermas, que em obras como A Constelação Pós-Nacional, A Inclusão do Outro e Sobre a Constituição da Europa, formulou uma interpretação sofisticada sobre os desafios colocados para a democracia em um contexto de conformação da "constelação pós-nacional", no qual o Estado nacional parece ter enfraquecido sua capacidade de ação como decorrência do adensamento de problemas que transcendem as fronteiras nacionais. Pensando especialmente a partir do contexto europeu e dos desafios hodiernos da União Europeia, Habermas tem procurado, por um lado, elaborar uma crítica aos processos de transnacionalização em curso, e, por outro, ressaltar as possibilidades democráticas e emancipatórias inscritas 
naquilo que definiu como "sociedade mundial de cidadãos" para a superação do déficit de integração social em âmbito transnacional (HABERMAS, 2001, 2002, 2012).

$\mathrm{O}$ argumento de Habermas se sustenta, de modo geral, em uma crítica imanente do processo de unificação europeu que, se por um lado, abriu possibilidades nunca antes pensadas para uma sociedade mundial constituída politicamente e para a construção de uma agenda cosmopolita radicalmente democrática, por outro, se reduziu a um instrumento administrado por uma elite funcional elitista, desinteressada e temerosa de uma participação mais efetiva da população. Habermas procura em suas intervençóes problematizar, de modo geral, o curso que tem seguido a globalização econômica, a qual, náo obstante politicamente desejada, não tem sido acompanhada por uma "coordenação política mundial”, bem como por uma "uma juridificação mais ampla das relaçóes internacionais" (HABERMAS, 2012, p. 116). Criticando as "ilusóes neoliberais", que acreditavam na ideia da autorregulaçáo dos mercados financeiros globais, Habermas defende a ideia segundo a qual somente uma política de regulamentação coordenada por uma comunidade cosmopolita de Estados e dos cidadãos do mundo será capaz de reconstituir o dilacerado tecido social europeu.

O ideal cosmopolita habermasiano se sustenta na noção de que não basta uma crítica moral das relaçóes injustas estratificadas da sociedade mundial; faz-se necessária, igualmente, a construção de uma agenda política que tenha como cerne a perspectiva de que defesa dos direitos humanos seja incorporada institucionalmente em uma sociedade mundial constituída politicamente. Para Habermas, os direitos humanos formam uma utopia realista na medida em que ancoram o próprio objetivo ideal de uma sociedade justa nas instituiçóes de um Estado constitucional. De acordo com o autor, existe historicamente um vínculo conceitual entre os conceitos de dignidade humana e direitos humanos, que se constitui como a base para a construção de uma utopia concreta verdadeiramente democrática. A dignidade humana se configuraria, dessa forma, como a fonte moral da qual os direitos humanos individuais, na modernidade, extrairiam seu conteúdo. Daí, sua perspectiva normativa se fundar na possibilidade da construção de uma agenda democrática cosmopolita que assuma estes dois conceitos como ancoragem e que seja capaz de construir instituiçóes, reunindo Estados e cidadáos do mundo, 
capazes de defendê-los e ampliá-los. Da mesma forma que a junção desses conceitos teria tido um "papel catalisador" para impulsionar, no curso da história, diversas transformaçóes democráticas, elas permaneceriam como as vigas de suporte de um projeto no qual, a partir da força civilizadora do direito estabelecido democraticamente, seria possível assegurar a construção de uma ordem democrática para a sociedade mundial contemporânea (HABERMAS, 2001, 2002).

A "utopia concreta" habermasiana tem como um de seus principais méritos a crítica nela inscrita a uma visão nacionalista estreita - fortemente presente tanto à esquerda, quanto à direita do quadro político -, que dificulta uma reflexão mais sistemática em torno da radicalidade democrática da agenda universalista dos direitos humanos. Para Habermas, aqueles que se opóem à agenda cosmopolita a partir de um nacionalismo acrítico não percebem o quanto o conceito de nação foi histórica e artificialmente construído - e, portanto, não deve ser naturalizado - e o quanto ele não dá mais conta de responder aos desafios colocados na conjuntura contemporânea. Habermas critica o fato de liberais e comunitaristas se prenderem a uma concepção acanhada de um Leviatâ, que se desenvolveu desde o século XVII com o sistema de estados europeus, e foi superada no curso das transformaçóes que se processaram no século XX. Os "apologistas da naçáo-povo" deixariam de perceber que os desafios da atualidade - relacionados, entre outras questóes, à "diferenciação multicultural da sociedade" - ultrapassam a capacidade de açáo dos Estados nacionais, demandando, por conseguinte, uma nova perspectiva que tenha em seu centro as instituiçôes supranacionais e as formas de socialização pós-nacionais (HABERMAS, 2002, p. 144).

Para Habermas, ainda que os direitos humanos só possam adquirir a validade positiva de direitos fundamentais em uma comunidade particular, isto é, no interior de um Estado nacional, sua pretensão universalista só pode ser concretizada em uma comunidade cosmopolita inclusiva, cuja normatividade aponta para as fronteiras transnacionais. Essa contradição entre nacional e universal só poderá, segundo o autor, ser resolvida em uma sociedade mundial constituída democraticamente. A concentraçáo da agenda política em âmbito nacional perde de vista justamente esse caráter cosmopolita e democrático da ideia de direitos humanos (HABERMAS, 2001, 2002). Isso não quer dizer que Habermas seja ingênuo quanto às possibilidades do uso da noção de 
direitos humanos para a imposição da agenda dos países desenvolvidos sobre o mundo subdesenvolvido ou para a legitimação de intervençóes pretensamente humanitárias, que não passam, na verdade, de açóes executadas com interesses escusos. Náo à toa, o autor reconhece que faz sentido, em certas situaçóes, a suspeita de que o programa dos direitos humanos consiste em seu mau uso imperialista, sobretudo quando ele se torna "um mero simulacro e veículo para impor os interesses das grandes potências" (HABERMAS, 2012, p. 33).

O uso deturpado da noção de direitos humanos para justificar imperialismos de toda sorte, contudo, não deve servir como razão suficiente para, nos termos de Habermas, "roubar a mais-valia moral própria dos direitos humanos e estreitar de antemáo o foco da temática dos direitos humanos" (HABERMAS, 2012, p. 33). Sua agenda, quando ancorada no conceito de dignidade humana, transcende as questóes comezinhas da política internacional, permitindo associar, de maneira mais ampla, as lutas nacionais e as universais em uma mesma dimensão. Para Habermas, "somente esse vínculo interno entre dignidade humana e direitos humanos produz aquela fusão explosiva da moral no médium direito, no interior do qual deve ser efetuada a construção das ordens políticas justas" (Idem, p. 37, grifos do autor). Nesse sentido, que o autor insiste na superação de uma concepção que associa diretamente soberania popular e soberania estatal. Ao contrário do pensá-los como conceitos dependentes, a soberania popular pode e deve ser encarada para além das fronteiras estatais. Para tanto, as competências transferidas ou distribuídas entre Estado nacional e as instâncias supranacionais devem ser não somente juridificadas no regime dos tratados internacionais, mas devem sê-lo "de forma democrática” (Idem, p. 56, grifo do autor). Nesse sentido, segundo Habermas, não basta que as instituiçôes sejam capazes de responder aos novos desafios colocados na ordem cosmopolita. Para que suas respostas sejam válidas, elas devem ser construídas democraticamente. Ou dito, de outra forma, o que está em jogo é a necessidade da institucionalização de novas relaçoóes que, superando a "sujeição inescrupulosa do mundo da via aos imperativos do mercado" (Idem, p. 111), sejam capazes de constituir democraticamente agendas universais, a partir de uma "comunidade cosmopolita inclusiva".

Para além da crítica ao nacionalismo estreito que perde de vista as potencialidades democráticas de uma perspectiva cosmopolita ancorada nas ideias de dignidade humana e direitos humanos, Habermas dirige sua intervençóes 
contra a tibieza dos partidos políticos europeus, em especial aqueles da esquerda, no sentido de "tematizar em geral" as alternativas para as decisóes de longo prazo. Preocupados com as próximas eleiçóes e subordinados em demasia à "opinião pública", os políticos não agiriam de forma independente, controlados a todo o momento pelos estados de ânimo rastreados a cada processo eleitoral. Presas a uma abordagem administrativa usual, absorvidos somente na busca por saídas imediatas para as atuais crises dos bancos, da moeda e da dívida, e pautando suas açóes em pesquisa de opiniấo, as elites políticas mostrar-se-iam incapazes de pensar o diferente e propor uma agenda normativa diversificada. Nesse sentido, o procedimento democrático perderia seu sentido principal. Ao contrário de existir para meramente retratar um aspecto espontâneo da opiniáo, este procedimento deveria reproduzir o resultado de um processo público de formação da opinião. Conforme destacado por Habermas, os votos dos eleitores apenas "recebem peso institucional da codeterminação democrática" caso estejam "vinculados a opinióes publicamente articuladas, que se formaram no intercâmbio comunicativo das tomadas de posição, das informaçóes e das razóes relevantes para o tema" (HABERMAS, 2012, p. 141-142, grifo do autor).

Uma evidência clara desse processo da fraqueza dessas elites políticas seria a inexistência nos países europeus de qualquer processo eleitoral ou referendo em que as pessoas fossem submetidas a uma verdadeira discussão e deliberação sobre aspectos diferenciados daqueles relacionados às temáticas e programas estritamente nacionais. Para Habermas, trata-se de um grande equívoco. O futuro da humanidade não estaria mais sendo jogado nos âmbitos restritos de um Estado nacional. Temáticas como a mudança climática, os riscos mundiais da tecnologia nuclear, a regulação do capitalismo impulsionado pelo mercado financeiro e a imposição dos direitos humanos em nível internacional, para serem efetivamente enfrentadas, demandariam esforços que transcenderiam as fronteiras nacionais, clamando a ação de uma comunidade cosmopolita de Estados e dos cidadáos do mundo. Daí, a necessidade de os partidos políticos europeus adotarem outra configuraçáo da mentalidade política, assumindo corajosamente a tarefa de suscitar o debate sobre estas temáticas internacionais, contribuindo, dessa maneira, para "configurar politicamente a opinião pública por meio de um esclarecimento permanente da população" (HABERMAS, 2012 p. 133). 
A partir de um diálogo crítico com as formulações de Habermas, variados autores, associados, de uma forma ou de outra, ao campo da teoria crítica vêm, ao longo dos últimos anos, buscando compreender e formular um diagnóstico crítico acerca das consequências das mudanças impulsionadas pela globalização e pelos processos de integração transnacional. Dentre esses autores, vale destacar especialmente os trabalhos produzidos por Seyla Benhabib e Craig Calhoun, cujas formulaçóes contribuem no sentido de se produzir uma crítica imanente aos processos de integração hodiernos do capitalismo neoliberal, de modo a compreender os impasses e aporias do cosmopolitismo contemporâneo, apontando para as possibilidades de resistência e emancipação.

\section{III}

Embora os primeiros trabalhos de Seyla Benhabib se inscrevam em uma reflexáo mais ampla sobre os pressupostos da teoria crítica e sobre a democracia deliberativa, ao longo dos últimos anos a autora tem deslocado sua agenda investigativa em direção a uma reflexão mais problematizada sobre a globalização e os processos de integração transnacionais, produzindo diversos trabalhos voltados para pensar temáticas relacionadas ao cosmopolitismo e ao sistema legal internacional. Em certo sentido, em suas abordagens sobre este objeto, a autora tem atualizado, ainda que sobre novas bases, preocupaçóes que atravessavam seus trabalhos anteriores sobre como reconciliar os princípios universais dos direitos humanos, da autonomia e da liberdade com identidades concretas particulares dos membros de comunidades humanas divididas por linguagens, etnias e religióes. A "virada cosmopolita" de Benhabib se verifica nos artigos que compóem obras como The Claims of Culture. Equality and Diversity in the Global Era, The Rights of Others. Aliens, Citizens and Residents, Another Cosmopolitanism: Hospitality, Sovereignty and Democratic Iterations e Dignity in Adversity. Human Rights in Troubled Times. Nos textos que compóem esses livros, Benhabib procura construir uma teoria crítica sobre o cosmopolitismo e a justiça global, que problematiza os elementos de dominação intrínsecos aos processos de integração transnacionais, ao mesmo tempo em que valoriza as potencialidades existentes para a construção de uma política democrática emancipatória pensada em uma perspectiva pós-nacional. Ancorada em seus pressupostos democráticos deliberativos, Benhabib sustenta a possibilidade de se pensar em um arcabouço legal transnacional que assegure a construção de 
um projeto de solidariedade pós-nacional, que transcenda as fronteiras estatais existentes (BENHABIB, 2002; 2004; 2006; 2011).

Segundo Benhabib, o mundo tem testemunhado, pelo menos desde o fim da Segunda Guerra Mundial, um movimento crescente no sentido da constituição de tratados e convenções firmadas entre diferentes nações voltadas para a configuração de um direito internacional cada vez mais amplo e sofisticado, do que são provas evidentes a Declaração Universal dos Direitos Humanos, de 1948, e as Convençóes de Genebra, voltadas, entre outros assuntos, para a proteção dos refugiados políticos. Nas últimas décadas, com o avanço da globalização e dos processos de integração transnacionais, tem havido, de acordo com Benhabib, uma maior ampliação da conformação de normas e legislaçóes cosmopolitas voltadas para a garantia e ampliaçáo dos direitos humanos, para o combate aos crimes contra a humanidade e para assegurar os direitos relacionados aos refugiados, imigrantes e asilados políticos. Para Benhabib, esses processos de integração crescente náo têm se dado sem conflitos e contradiçóes, na medida em que eles têm como corolário principal o desafio de se repensar as complexas relações entre as soberanias nacionais dos países signatários dessas normas e a ampliação crescente de direitos cosmopolitas, que procuram justamente transcender as fronteiras dos Estados nacionais. É justamente diante desse quadro que se coloca o desafio para a teoria crítica em refletir sobre a conciliação entre, de um lado, as reivindicaçóes de autodeterminação soberana dos povos nacionais, e, de outro, as demandas pela adesão aos princípios universais dos direitos humanos (BENHABIB, 2002; 2006).

É precisamente em torno dessas relaçóes que Benhabib, em diálogo com as reflexões de Imannuel Kant, Hannah Arendt e Habermas, procura construir suas proposiçóes em torno da noção de cosmopolitismo, com o intuito de conciliá-la com a soberania democrática, que historicamente tem sido pensada em termos de Estado-nação. De acordo com a autora, esse processo crescente de ampliação das normas e legislaçóes cosmopolitas tem sido acompanhado paralelamente por outros movimentos de integração transnacionais, vinculados principalmente à expansão das forças do capitalismo, que também conduzem a um enfraquecimento da soberania estatal, desafiando o poder das legislaturas democráticas nacionais. Nesse caso específico, o que se busca é um processo de "desjuridificação", mediante a multiplicação de zonas que procuram enfraquecer o controle da lei e a presença do Estado em diferentes 
territórios, criando-se enclaves sem accountability democrática e sem a supervisão parlamentar. Viveríamos, portanto, um momento contraditório de ampliação da constitucionalizaçâo global democrática e da desjuridificação pelas forças do mercado, ambas significando um aumento dos processos de integração transnacionais. Contudo, de acordo com a autora, se o primeiro movimento de integração - vinculado à ampliação de um direito internacional orientado para a proteçáo das minorias - pode e deve ser pensado como passível de conciliação com as demandas por cidadania e soberania democráticas configuradas no âmbito dos Estados nacionais, o mesmo não ocorre com o segundo movimento, mais associado à expansão das regras estabelecidas pelos mercados, que procuram precisamente desestruturar direitos outrora conquistados. Cabe a uma teoria crítica da justiça global saber diferenciar o caráter das normas e legislaçóes globais, identificando aquelas que contribuem para fortalecer processos em curso de democratização e de emancipaçáo dos povos, daquelas que, pelo contrário, atuam no sentido de manter as relaçóes de opressão e as desigualdades sociais (BENHABIB, 2004; 2006).

Nessa perspectiva, é possível dizer que o objetivo de Benhabib se vincula a, de um lado, criticar setores à esquerda e à direita que contestam os processos de integração global como seu eles fossem, a priori, imperialistas e opressores e, de outro lado, problematizar aqueles que naturalizam esses movimentos de transnacionalização como se eles fossem positivos em sua totalidade. De uma parte, a crítica nacionalista, seja ela progressista ou conservadora, sustenta, segundo a autora, uma visão paroquial, que não compreende os potenciais emancipatórios de muitas dessas normas e legislaçóes globais, que contribuem quer para minar mecanismos de exploração internos às fronteiras nacionais atuando, ao menos, como pressão sobre os países signatários -, quer para assegurar a proteçáo de minorias, como imigrantes, refugiados, asilados políticos, possibilitando a constituição de redes e de estratégias voltadas para a expansão de um ativismo global em torno da agenda dos direitos humanos. A normatização cosmopolita pode contribuir, nesse sentido, para que novas subjetividades adentrem na esfera pública e alterem significativamente as reivindicaçóes que têm curso nesse espaço, fortalecendo sobremaneira os movimentos de resistência às forças do capitalismo global. De outra parte, aqueles que aceitam por completo e acriticamente os processos de integração global não percebem que muitas das normas internacionais criadas no bojo da globalização o foram com o intuito de impulsionar movimentos de dominação, destruir 
direitos e assegurar única e exclusivamente o avanço sem freios do capital, com seus movimentos de mercantilização e comoditização da vida social e política (BENHABIB, 2011).

À teoria crítica caberia, segundo Benhabib, uma análise mais dialética e matizada desses processos de integraçáo transnacionais, problematizando suas características opressoras e valorizando seus potenciais democráticos. Nesse sentido que Benhabib formula seu conceito de iteraçôes democráticas, que, segundo ela, indicaria a possibilidade da conjugação entre as normas internacionais e os processos de soberania nacionais, tendo como horizonte normativo uma agenda cosmopolita e pós-nacional, ancorada em um "universalismo moral”, orientada para a potencialização das interconexóes entre o local, o nacional e o global. As "iteraçôes democráticas" consistiriam em processos complexos de argumentação e de deliberação pública, mediante os quais as reivindicaçóes de direito universais seriam contestadas e contextualizadas nacionalmente e localmente, tanto no âmbito das instituiçóes políticas, quanto nas esferas públicas nacionais. Nesse sentido, parte-se do pressuposto de que as normas cosmopolitas podem ser reconciliadas, ainda que nunca perfeitamente, através da argumentação pública e deliberação em atos de iteraçóes normativas nos contextos nacionais. As normas cosmopolitas, nesta perspectiva, requerem uma contextualização local, uma interpretação e um debate permanente por parte de pessoas autônomas, que serão diretamente afetadas pelos novos arranjos globais estabelecidos (BENHABIB, 2006).

De acordo com Benhabib, nessa perspectiva, uma teoria cosmopolita de justiça não poderia estar restrita a esquemas de "justa distribuição" na escala global, devendo também incorporar a ideia de um justo pertencimento, que envolveria o reconhecimento das reivindicaçóes das minorias globais, a sustentação de um regime de fronteiras porosas e a defesa de um sistema capaz de assegurar aos seres humanos, nos termos de Hannah Arendt, "o direito a ter direitos", independente do status de seu pertencimento político. Nesse sentido, o "cosmopolitismo federalista" de Benhabib não pretende se opor ao Estado-nação, mas, pelo contrário, procura demonstrar que somente com modelos transnacionais de cooperaçáo, colaboração e solidariedade será possível preservar os valores fundamentais que ancoraram historicamente a construção dos direitos e da cidadania nos Estados nacionais (BENHABIB, 2011).

Dessa forma, o que Benhabib vem buscando realizar é, mediante a construçáo de uma teoria crítica sobre a justiça global e as normas cosmopolitas, 
destacar os perigos contemporâneos relacionados aos processos de integração - associados, em grande medida, ao enfraquecimento da soberania popular e à privatizaçáo da soberania dos Estados nacionais -, mas, ao mesmo tempo, enfatizar as possibilidades abertas para a construçáo de um direito global, mediante a constituição de novas "iteraçóes democráticas", que permitam a formulação de normas cosmopolitas orientadas para a proteçáo das minorias e para o fortalecimento de processos democráticos e emancipatórios.

\section{IV}

No que concerne à reflexão sobre a temática do cosmopolitismo no campo da teoria crítica, merecem destaque especial os trabalhos de Craig Calhou sobre o tema, sobretudo pelo fato de os escritos do autor abrirem caminhos para se matizar um otimismo em relação à agenda cosmopolita, que atravessa, de diferentes maneiras, as abordagens de Habermas e de Benhabib. Nos últimos anos, Calhoun tem dedicado especial atenção ao cosmopolitismo, sobretudo por sua aproximaçáo cada vez mais destacada à temática da identidade e do nacionalismo, como fica evidente no livro por ele organizado Social Theory and the Politics of Identity (1994) e na obra de sua autoria Nationalism (1997). Contudo, se as questóes que inquietavam o autor relacionadas a este objeto já apareciam nestes trabalhos dos anos 1990, elas ganharam maior sistematicidade no decorrer na primeira década de 2000, quando Calhoun produziu os artigos que compóem seu livro Nation Matter: Citizenship, Solidarity, and the Cosmopolitan Dream (2007). Nesses trabalhos, Calhoun procurou estabelecer um diálogo direto com as formulaçóes dedicadas à compreensão da globalização e dos processos de integraçáo transnacionais, construindo uma formulação bem mais crítica à noção de cosmopolitismo do aquela defendida, por exemplo, por Habermas e Benhabib. Ainda que reconheça a importância de a teoria crítica elaborar uma construção teórica e política em torno de uma agenda cosmopolita, Calhoun acredita que isso náo possa ser feito reduzindo a importância das tradiçóes nacionais, como comumente ocorre. De acordo com o autor, as abordagens cosmopolitas, em geral, cometem um duplo equívoco: do ponto de vista analítico, exageram o diagnóstico da existência de um mundo cosmopolita, náo percebendo o quanto este processo ainda se encontra restrito e desigual; da perspectiva normativa, os teóricos do cosmopolitismo extrapolam suas crenças na política cosmopolita, reduzindo, ou até mesmo, ignorando, a importância das tradiçôes nacionais para a construção de um imaginário político democrático e emancipatório. 
De acordo com Calhoun, a noção de cosmopolitismo tem estado na moda, tendo adquirido nos últimos anos uma enorme força retórica no debate teórico e político. Embora a ideia de cosmopolitismo seja bem antiga, remontando a Diógenes de Sinope, ela vivenciou, ao longo dos séculos, uma série de transformações conceituais desde os filósofos estoicos de Roma, passando pelos europeus renascentistas e pelos filósofos iluministas, com especial destaque para Kant, até chegar a teóricos contemporâneos, como Habermas e Beck, adquirindo nas últimas décadas uma enorme legitimidade nos debates públicos e no senso comum. Diversas transformaçóes que se processaram nos últimos anos, relacionadas, por exemplo, à queda do comunismo, ao avanço da globalização, ao desenvolvimento de novos meios de comunicação e à ampliação das esperanças quanto às possibilidades da configuração de uma nova ordem global - sustentada na ideia de direitos humanos universais -, aliadas ao reconhecimento crescente segundo o qual a humanidade está unida por um mesmo destino e submetida aos mesmos desafios e riscos, tornaram, de certa forma, imperativa a discussão em torno da ideia do cosmopolitismo, tanto em uma perspectiva teórica quanto política (CALHOUN, 2007).

Apesar das diferenças existentes nas formulaçóes contemporâneas, a definição hegemônica do termo se consolidou em torno da noção segundo a qual ser cosmopolita significaria se comportar "acima" ou "além" das naçóes, orientado por uma ética universal abstrata, que rejeitaria ou, pelo menos, superaria as culturas, valores e tradiçóes nacionais, tomadas como necessariamente restritivas, separatistas e repressoras. No discurso cosmopolita, dessa maneira, a defesa de uma visão mais ampla e abrangente do mundo pressuporia a transcendência da própria ideia de nação, que daria lugar a um suposto compromisso com a humanidade como um todo. Para Calhoun, contudo, é necessário problematizar esta perspectiva. Segundo ele, tal formulação, além de implicar frequentemente na confusão da noção de universalismo cosmopolita com as concepçóes ocidentais - legitimando toda sorte de imperialismos e de "intervençôes humanitárias" que reforçam relaçóes de poder e dominação -, acaba por pressupor a ideia segundo a qual o mundo cosmopolita já seria uma realidade ou, pelo menos, uma opção para todos, ignorando o fato de que ser cosmopolita, pelo menos nos termos propostos, tem sido apenas uma possibilidade para poucos, justamente aqueles mais bem providos de capital material, simbólico e cultural (CALHOUN, 2007). 
Nesse sentido, os textos de Calhoun direcionam-se no sentido de matizar a euforia em torno da agenda cosmopolita e reforçar a necessidade de a teoria crítica dedicar uma atenção mais destacada, sem qualquer sorte de preconceitos, à temática do nacionalismo. Não restam dúvidas de que as consequências perversas da globalização - como, por exemplo, os abusos dos direitos humanos, a proliferação de doenças endêmicas, a ampliaçáo dos crimes globais e a intensificação de problemas vinculados à imigração e aos refugiados - demandam respostas globais e transnacionais. Mas, segundo o autor, seria um equívoco pensar que elas podem ser resolvidas sem os Estados nacionais. Estas e outras questóes transnacionais reclamariam, pelo menos em parte, mais e náo menos Estado. Além disso, as questóes problemáticas do mundo contemporâneo não seriam apenas globais, mas também nacionais e locais, exigindo, por conseguinte, uma participação mais ativa de poderes intermediários, vinculados aos Estados nacionais (CALHOUN, 2007).

Para Calhoun, uma coisa é a crítica cosmopolita reconhecer os limites do exercício do poder estatal nacional, identificando que ele tem sido utilizado por forças conservadoras, legitimando conservadorismos, preconceitos, separatismos e práticas diversas de atrocidades, como, por exemplo, limpezas étnicas. Outra, bem diferente, é buscar transcendê-lo por completo, ignorando, de uma parte, sua importância para a construçáo histórica das democracias modernas e de práticas de diversidade em larga escala, e, de outra parte, seu papel no sentido de assegurar uma experiência de pertencimento em um mundo no qual as pessoas parecem perder suas tradicionais formas de ancoragem. Uma coisa é encorajar a agenda cosmopolita e os necessários processos de integração da sociedade civil global; outra, completamente diversa, é acreditar que esses processos seráo a panaceia para a resoluçáo de todos os problemas, condenando-se o nacionalismo como uma herança envelhecida e imaginando que a democracia possa ser construída sem Estados nacionais efetivos e sem as redes de solidariedade por ele asseguradas (CALHOUN, 2007).

Dessa maneira, para Calhoun, as formulaçóes cosmopolitas têm, por um lado, exagerado no otimismo em relação à globalização e aos processos de integração transnacionais - ignorando, inclusive, o quanto eles têm sido utilizados pelas forças neoliberais para impulsionar, sem maiores resistências, os avanços das forças de mercado - e, por outro lado, concentrado suas atençóes única e exclusivamente no "mau nacionalismo", negligenciando sua 
importância quer para fortalecer as instituiçóes públicas nacionais em tempos de globalização neoliberal assimétrica, quer, sobretudo, para assegurar a configuraçáo de laços de solidariedade vitais para a construçáo de projetos de inclusão social e de justiça distributiva. Para Calhoun, um dos principais problemas vinculados às teorias cosmopolitas adviria do fato de elas serem normativamente individualistas e abstratas, não percebendo que o cosmopolitismo por eles defendido não é de todo "neutro", estando ancorado em determinadas instituiçóes, tradiçóes e valores particulares, identificados, em grande medida, com o mundo ocidental. Segundo Calhoun, a defesa de uma agenda cosmopolita supostamente abstrata acaba por negligenciar a importância de outras tradiçóes e culturas nacionais para a construção de projetos democráticos e emancipatórios. O cosmopolitismo, nesta perspectiva, pode e deve ser desejado, mas não nos termos individualistas e abstratos como querem seus teóricos contemporâneos, mas sim ancorado em solidariedades, tradiçóes, culturas e valores nacionais concretos, que têm sido sistematicamente ameaçados pela globalização capitalista neoliberal (CALHOUN, 2007).

Por este ângulo de análise, é possível dizer que, embora ressalte a importância da categoria "cosmopolitismo" para se pensar uma ordem democrática e emancipatória, Calhoun preocupa-se em como articular a questáo da naçáo às dimensóes universalistas do cosmopolitismo. Esta articulação se faz necessária até mesmo porque, segundo o autor, o Estado nacional não perdeu na atualidade sua importância nem do ponto de vista analítico - na medida em que continua como uma importante categoria, tanto como ideologia, quanto como modo de organização prática -, nem do ponto de vista normativo, posto que o Estado Nação permanece como espaço central de articulação de solidariedades diversas e de construçáo do bem comum. De maneira paradoxal, a globalização fez com que o pertencimento ao Estado-nacional, com o corolário de direitos a ele associados, se tornasse mais, e não menos importante, nesse contexto de intensificação dos processos de integração transnacionais. Não se trata, é claro, de uma formulaçáo voltada para a obliteração das conexôes globais, mas sim de uma aposta no fato de que estas conexôes devem estar sustentadas em laços de solidariedade social, que são forjados no interior das próprias naçóes. O que está em jogo para o autor é a construção de uma espécie de cosmopolitismo de conexóes, a partir do qual os seres humanos se articulariam não apenas a partir de uma igualdade abstrata, mas por 
relacionamentos interpessoais e instituições sociais concretas, constituídas no interior dos Estados nacionais, e que permitem o estabelecimento de redes de conexóes entre diferentes grupos portadores de dinâmicas culturas, valores e tradições locais (CALHOUN, 2007).

Mais do uma simples defesa acrítica do nacionalismo, trata-se, para Calhoun, de mostrar a importância e as potencialidades dos Estados nacionais para a construção de uma ordem mais democrática, ainda que reconhecendo seus perigos e problemas. Pensar a centralidade das tradiçóes nacionais seria ainda mais necessário em um contexto como o contemporâneo, marcado por profundas transformaçóes da ordem neoliberal, a qual, não obstante sua força e resiliência, vem apresentando fissuras e sendo problematizada por suas consequências perversas, como evidenciam, por exemplo, os artigos da coleçáo organizada por Calhoun sobre a crise econômica de 2008, que parece, ao menos, ter recolocado na agenda teórica e política a importância dos Estados nacionais (CALHOUN e DERLUGIAN, 2011). A teoria crítica, nessa perspectiva, deveria, segundo Calhoun, direcionar seus esforços no sentido de pensar uma agenda cosmopolita que não se ancorasse em uma abstração universalista e individualista, mas em uma perspectiva que, sem perder o horizonte normativo universal, estivesse conectada com a pluralidade e riqueza das diversas culturas e tradiçóes nacionais, fontes permanentes de solidariedade em um mundo em constante processo de mudanças.

No decorrer deste artigo procuramos demonstrar de que maneira a teoria crítica - especialmente aquela representada Fraser, Habermas, Benhabib e Calhoun - se apresenta como uma fonte sofisticada de relevantes contribuiçóes no sentido de interpretar as transformaçóes vinculadas à globalizaçáo e aos processos de integraçáo transnacionais. A teoria tridimensional de Fraser para refletir sobre a justiça no contexto do enquadramento "pós-Westfaliano", a proposta de Habermas em torno da "constelaçáo pós-nacional" e da "sociedade mundial de cidadãos", as formulações de Benhabib sobre os processos de constitucionalização global e a importância de construção de uma agenda ancorada nas "iteraçôes democráticas" para potencializar as possibilidades abertas pelo cosmopolitismo e as contribuiçóes de Calhoun no sentido de valorizar as tradiçóes, culturas e valores nacionais para a construção de um 
"cosmopolitismo de conexões", são exemplares de formulaçóes que, a despeito de suas particularidades e diferenças, convergem no sentido de promover uma crítica imanente à globalização e aos processos de transnacionalização, ressaltando seus aspectos ambivalentes e contraditórios de opressão e emancipação.

De acordo com Gerald Delanty (2012) em seu livro The Cosmopolitan Imagination. The Renewal of Critical Social Theory, uma sociologia crítica do cosmopolitismo deve ter como principal desafio a compreensão dos processos políticos, econômicos e sociais em curso, identificando realidades e atores sociais emergentes. Os escritos de Fraser, Habermas, Benhabib e Calhoun são exemplares de esforços empreendidos nessa direção, orientados para a construçáo de uma teoria crítica dos processos globais e transnacionais em curso, que problematiza aspectos da agenda cosmopolita - ainda que alguns o façam com menos força do que outros, a exemplo de Calhoun e Fraser em comparação com Habermas e Benhabib -, mas que náo deixa de apostar na possibilidade da construção de uma política universalista, democrática e emancipatória. De maneira geral, os trabalhos destes autores evidenciam a vitalidade e a capacidade da teoria crítica contemporânea no sentido de formular diagnósticos e apontar para as aporias e desafios do tempo presente.

\section{Referências}

BAUMAN, Z. Globalization: the human consequences. Cambridge: Polity Press, 1998.

BECK, Ü. O que é globalização. São Paulo: Paz e Terra, 1999.

Cosmopolitan vision. Cambridge: Malden, Polity, 2006.

BECK, Ü. et al. Modernização reflexiva: política, tradição e estética na ordem social moderna. São Paulo: UNESP, 1995.

BENHABIB, S. Critique, norm and utopia: a study of the foundations of critical theory. New York: Columbia University Press, 1986.

The claims of culture: equality and diversity in the global era. Princeton: Princeton University Press, 2002.

The right of others: aliens, citizens and residents. Cambridge: Cambridge University Press, 2004. 
Another cosmopolitanism: hospitality, sovereignty and democratic iterations. Oxford: Oxford University Press, 2006.

Dignity in adversit: human rights in troubled times. United Kingdom: Polity Press, 2011.

BOLTANSKI, L.; CHIAPELLO, E. Le nouvel esprit du capitalisme. Paris: Gallimard, 1999. BURAWOY, M.l et. al. (Eds.) Facing an unequal world: challenges for a global sociology. Taiwan, Institute of Sociology at Academia Sinica; Council of National Associations of the International Sociological Association, and Academia Sinica, 2010.

CALHOUN, C. Critical social theory: culture, history and the challenge of difference. Oxford and Cambridge: Basil Blackwell, 1995.

Nationalism. Buckingham: University of Minnesota Press, 1997.

Nations matter: culture, history, and the cosmopolitan dream. New York: Rutledge, 2007.

CHERNILO, D. Nacionalismo y cosmopolitismo: ensayos sociologicos. Santiago: Ed. Universidad Diego Portales, 2010.

COSTA, S. “Teoria social, cosmopolitismo e constelação pós-nacional”. Novos estudos Cebrap, n. 59, p. 4-19, 2001.

DELANTY, G. The cosmopolitan imagination: the renewal of critical social theory. Cambridge: Cambridge University Press, 2009.

. (Ed.). Handbook of cosmopolitanism studies. New York: Routledge, 2012.

DOMINGUES, J. M. Interpretando a modernidade: imaginário e instituiçóes. Rio de Janeiro: Editora FGV, 2002.

. "Vicissitudes e limites da teoria crítica hoje". Sociologia \& antropologia, p. 71-89, 2011.

FINE, R. Cosmopolitanism: key ideas. London, Routledge, 2007.

FRASER, N. "Rethinking the public sphere: a contribution to the critique of actually existing democracy". In: C. Calhoun (Ed.). Habermas and the public sphere. Cambridge, MIT Press, p. 109-142, 1992.

Reframing justice: the 2004 spinoza lectures. Amsterdam: Van Gorcum, 2005. 
Scales of justice: reimagining political space in a globalizing world. New York: Columbia University Press, 2008. et al. Transnationalizing the public sphere. Cambridge. Polity Press, 2014.

GIDDENS, A. The Consequences of modernity. Cambridge: Polity Press, 1990.

HABERMAS, JÜRGEN. A constelaçáo pós-nacional: ensaios políticos. São Paulo: Editora Littera Mundi, 2001.

A inclusáo do outro: estudos de teoria e política. São Paulo: Loyola, 2002.

Sobre a constituição da Europa: um ensaio. São Paulo: Editora UNESP, 2012.

HARVEY, D. Cosmopolitanism and the geographies of freedom. New York: Columbia University Press, 2009.

MÜLlER-DOOHM, S. "How to Criticize: Convergent and Divergent Paths in Critical Theories of Society". In: Delanty, Gerard (Org.). Handbook of european social theory. Londres/ Nova York: Routledge, 2005.

NOBRE, M. “Teoria crítica: uma nova geração". Novos estudos Cebrap, v. 93, p. 23-27, 2012.

ORTIZ, R. A diversidade dos sotaques: o inglês e as ciências sociais. São Paulo: Brasiliense, 2008.

REIS, E. "O Estado Nacional como Desafio Teórico e Empírico para a Sociologia Política Contemporânea”. In: L. Schwartzman et al. (Orgs.). O sociólogo e as políticas públicas. Rio de Janeiro: Editora FGV, 2009.

ROBERTSON, R. Globalization: social theory and global culture. London: Sage, 2002.

SANTOS, B. S. (Org.). Reconhecer para libertar: os caminhos do cosmopolitismo multicultural. Rio de Janeiro: Civilização Brasileira, 2003.

VANDENBERGHE, F. “Um Estado para o Cosmopolitismo”. Novos estudos Cebrap, v. 90, p. $85-101,2011$. 


\section{Critical Theory and Contemporary New Challenges: globalization, cosmopolitanism and democracy}

\section{Abstract}

During the last decades the field of social theory has seen the significant increase in the number of reflections on globalization and cosmopolitanism. Among the many efforts in this direction, the work of authors associated with critical theory, such as Jürgen Habermas, Nancy Fraser, Seyla Benhabib and Craig Calhoun, stand out. This article aims to analyze how these thinkers have approached these issues, showing how their recent work, despite differences, bear resemblances in that they seek to understand dialectically, in light of critical theory, the processes of globalization and intensifying cosmopolitanism in recent years. We intend to demonstrate that their reflections on these themes contribute to a critical perspective on cosmopolitanism and globalization, yet without leading to a rejection of a universal, democratic and emancipatory project.

Keywords: Critical theory. Globalization. Cosmopolitanism. Democracy.

Recebido em 05/03/2016

Aceito em 22/11/2016 